\title{
A Multiplex Genome Editing Method for Escherichia coli Based on CRISPR-Cas12a
}

\begin{abstract}
Xiang Ao ${ }^{1,2,3,4 t}$, Yi Yao ${ }^{1,3,47}$, Tian Li ${ }^{5}$, Ting-Ting Yang ${ }^{3}, X u$ Dong $^{3}$, Ze-Tong Zheng ${ }^{3}$, Guo-Qiang Chen ${ }^{1,2,3,4}$, Qiong Wu ${ }^{1,3,4 *}$ and Yingying Guo ${ }^{6 *}$
\end{abstract}

${ }^{1}$ MOE Key Laboratory of Bioinformatics, Center for Synthetic and Systems Biology, Tsinghua University, Beijing, China, ${ }^{2}$ Tsinghua-Peking Center for Life Sciences, Tsinghua University, Beijing, China, ${ }^{3}$ School of Life Sciences, Tsinghua University, Beijing, China, ${ }^{4}$ Center for Synthetic and Systems Biology, Tsinghua University, Beijing, China, ${ }^{5}$ China National Center for Biotechnology Development, Beijing, China, ${ }^{6}$ State Key Laboratory of Environmental Chemistry and Ecotoxicology, Research Center for Eco-Environmental Sciences, Chinese Academy of Sciences, Beijing, China

Various methods for editing specific sites in the Escherichia coli chromosome are available, and gene-size ( $\sim 1 \mathrm{~kb})$ integration into a single site or to introduce deletions, short insertions or point mutations into multiple sites can be conducted in a short period of time. However, a method for rapidly integrating multiple gene-size sequences into different sites has not been developed yet. Here, we describe a method and plasmid system that makes it possible to simultaneously insert genes into multiple specific loci of the $E$. coli genome without the need for chromosomal markers. The method uses a CRISPR-Cas12a system to eliminate unmodified cells by doublestranded DNA cleavage in conjunction with the phage-derived $\lambda$-Red recombinases to facilitate recombination between the chromosome and the donor DNA. We achieved the insertion of up to 3 heterologous genes in one round of recombination and selection. To demonstrate the practical application of this gene-insertion method, we constructed a recombinant $E$. coli producing an industrially useful chemical, 5-aminolevulinic acid (ALA), with high-yield. Moreover, a similar two-plasmid system was built to edit the genome of the extremophile Halomonas bluephagenesis.

Keywords: CRISPR-Cas12a, synthetic biology, multiplex genome editing, E. coli, Halomonas

\section{INTRODUCTION}

Efficient methods for the introduction of heterologous genes into microbial hosts are indispensable for metabolic engineering and industrial strain construction, and a number of techniques have been developed to provide easy ways to introduce gene insertions or deletions into the genome of Escherichia coli. Prominent examples include group II intron retro-homing (Karberg et al., 2001; Enyeart et al., 2013) and recombination-mediated genetic engineering (recombineering) (Datsenko and Wanner, 2000; Heermann et al., 2008; Sharan et al., 2009). Recombineering, in particular, is commonly used for precise editing of the E. coli genome. With the assistance of phage-derived recombinases ( $\lambda$-Red and RecET), efficient DNA integration can be accomplished through recombination between donor DNA and the chromosome at a specific, pre-defined site. However, this process requires the presence of a selectable marker to counter-select the wild-type strain (Yu et al., 2008; Yang et al., 2014), and therefore also necessitates a further step to remove the marker, leaving behind a scar site in some cases (Sukhija et al., 2012; Esvelt and Wang, 2013). As a 
consequence, for multiplex genome engineering, these methods are time-consuming. Multiplex automated genome engineering (MAGE) (Wang et al., 2009) and co-selection MAGE were developed to perform genomic manipulation through pointmutations or (and) short insertions, but both methods are not suitable for performing gene-size (about $1 \mathrm{~kb}$ ) insertions.

Recently, the clustered regularly interspaced short palindromic repeats (CRISPR)/CRISPR-associated protein (Cas) system (Mojica et al., 2005; Jiang et al., 2013) has been coupled with the $\lambda$-Red system to accomplish efficient editing of the E. coli genome (Jiang et al., 2015; Li et al., 2015; Pyne et al., 2015; Reisch and Prather, 2015; Zhao et al., 2016; Chung et al., 2017; Zhang et al., 2017). In such methods, double stranded DNA cleavage by the CRISPR-Cas system is used to counter-select against wild-type cells (Chayot et al., 2010). The CRISPR-based selection strategy therefore enables rapid and scarless genomic editing. However, even though some groups achieved simultaneous modifications of up to three genes (Jiang et al., 2015; Li et al., 2015), gene insertions at multiple loci were not performed. In a different approach, Bassalo et al. (2016) developed a strategy to integrate large metabolic pathways into the E. coli genome at a single locus. However, when the integrated pathway was further edited in vivo, deletions across the targeted site were observed frequently, suggesting recombination between repetitive elements (e.g., promoters and terminators). Therefore, a promising solution, for further manipulation of the genome, is to divide the metabolic pathway into several parts and insert these components into different sites.

Lately, a novel type V-A CRISPR-Cas system - CRISPRCas12a (CRISPR-Cpf1) (Zetsche et al., 2015), was described. Distinct from CRISPR-associated protein 9 (Cas9), Cas12a is a single RNA-guided endonuclease, which utilizes a different protospacer-adjacent motif (PAM) and leaves sticky ends after DNA cleavage (Zetsche et al., 2015). Compared with the commonly used Streptococcus pyogenes Cas9 (SpCas9), the Francisella novicida Cas12a (FnCas12a) harnessed in this research has a smaller size, follows the guidance of a dual CRISPR RNA (crRNA), and utilizes a T-rich PAM (Zetsche et al., 2015). The smaller size of Cas12a decreases the metabolic burden imposed on the host cells, and makes it easier for researchers to handle the corresponding material (e.g., in plasmid construction, electroporation, etc.). The CRISPR-Cas12a system has been adopted for genome editing in several bacterial species, including Corynebacterium glutamicum (Yu et al., 2017), E. coli, Yersinia pestis, and Mycobacterium smegmatis (Yan et al., 2017). Although genomic manipulation at a single site was achieved in E. coli, an efficient method that can be used to simultaneously perform multiplex gene insertions is needed to achieve time and cost savings.

Here, we describe a rapid and efficient method to edit the E. coli chromosome at multiple sites simultaneously and a recombinant $E$. coli integrated with three heterologous genes was obtained within 8 days. By simultaneously integrating the T7 RNA polymerase gene and the T7 promoter-driven ALA synthase gene into two separate loci, this system was employed to construct a strain for the efficient production of an industrially useful chemical - ALA (Liu et al., 2014). In addition, the modification of the atypical extremophilic host Halomonas using CRISPR-Cas9 (Qin et al., 2018) demonstrates the power of gene editing in different bacterial species. To test the potential of this method in editing other types of bacterial genomes, a similar two-plasmid system based on CRISPR-Cas12a was built to edit the genome of the extremophile $H$. bluephagenesis.

\section{RESULTS}

\section{Construction of the Two-Plasmid System}

The genome editing method uses a CRISPR-Cas12a system, including Cas12a and corresponding crRNA(s), to eliminate unmodified wild-type cells by double-stranded DNA cleavage, in conjunction with the phage-derived $\lambda$-Red recombinases to facilitate recombination between the chromosome and the donor DNA. With CRISPR-Cas12a-mediated restriction to eliminate unmodified cells, homologous sequences in the donor plasmid as templates, and $\lambda$-Red to accelerate recombination, we assumed to achieve genomic modifications when all conditions were met. It is worth mentioning that, differing from linear templates (PCR products or DNA oligos), circular templates (donor DNAs in high copy-number plasmids with the pUC origin) were adopted in this study to increase their concentration. We believed that the increase in template concentration should make multiplex engineering possible. The two-plasmid system was composed of a helper plasmid and a donor plasmid (Table 1). The helper plasmid series comprised the $\lambda$-Red recombinase expressed under the control of the anhydrotetracycline (aTc)-inducible promoter $\mathrm{P}_{\text {tet }}$, and the Cas protein (Cas9 or Cas12a) expressed under the control of the arabinose-inducible promoter $\mathrm{P}_{\mathrm{araB}}$ (Guzman et al., 1995; Cha et al., 1997) (Figure 1A). Because the $\mathrm{P}_{\mathrm{araB}}$ promoter is repressed in presence of high glucose concentration (Guzman et al., 1995), glucose was used for inhibition of the expression of Cas12a. The donor plasmid series comprised the guide RNA(s) expressed constitutively via the J23119(SpeI) promoter (Liu et al., 2011), and donor DNA(s) as editing template(s) comprising a heterologous gene flanked by two 500 bp homologous arms, a left arm (LA) and a right arm (RA) (Figure 1B). Schematic maps of the donor plasmid p46Cpf1 with the native FnCas12a (FnCpf1) gene and the helper plasmid pTc-GLP which provides donor DNAs and crRNAs for three different sites are shown in Figures 1A,B, respectively. The plasmid construction process was described in Supplementary Tables S1, S2.

In the two-plasmid system, effects of different components on inducible cell killing were tested (Figure 2). Cas12a processes the transcript from the donor plasmid to generate mature crRNAs (Fonfara et al., 2016). Guided by the crRNA, Cas12a finds the genomic target and induces a double-strand break (Zetsche et al., 2015) (Figure 2A). Recombination occurs between the genomic target and the donor DNA mediated by $\lambda$-Red (Sharan et al., 2009). We introduced intact or deficient donor plasmids into bacteria harboring the helper plasmid p46Cpf1 by electroporation. The total colony number of forming units (CFUs) refers to the number of competent cells prepared for each electroporation. The rate of CFU to total CFU indicated 
TABLE 1 | Bacterial strains and plasmids used in this study.

\begin{tabular}{|c|c|c|}
\hline Strains or plasmids & Characteristics & Source \\
\hline \multicolumn{3}{|l|}{ Strains } \\
\hline E. coli MG1655 & F-lambda- rph-1 & CGSC 6300 \\
\hline H. bluephagenesis TD01 & H. bluephagenesis wild type & Cai et al., 2011 \\
\hline E. coli MG1655AX01 & MG1655 storS::p103-hem1 & This study \\
\hline E. coli MG1655AX02 & MG1655 slacZ::T7 RNAP, $\Delta$ torS::pT7-hem1 & This study \\
\hline E. coli MG1655AX03 & MG1655 with the plasmid pLTT05 & This study \\
\hline \multicolumn{3}{|l|}{ Plasmids } \\
\hline pcrRNA-P & crRNA-pyrF, pUC origin, kan & This study \\
\hline p46Cas9 & Expressing $\lambda$-Red and SpCas9 & This study \\
\hline p46Cpf1 & Expressing $\lambda$-Red and wild-type FnCas12a (FnCpf1) & This study \\
\hline p46Cpf1-OP1 & Expressing $\lambda$-Red and codon-optimized FnCas12a (type 1) & This study \\
\hline p46Cpf1-OP2 & Expressing $\lambda$-Red and another codon-optimized FnCas12a (type 2) & This study (Addgene \#98592) \\
\hline pTs-P & sgRNA-pyrF, $\Delta p y r F:: g f p$ & This study \\
\hline pTs-PL & sgRNA-lacZ, $\Delta$ lacZ::aadA sgRNA-pyrF, $\Delta p y r F:: g f p$ & This study \\
\hline pTs-GLP & sgRNA-galK, $\Delta$ galK::Ifp sgRNA-lacZ, $\Delta$ lacZ::aadA sgRNA-pyrF, $\Delta p y r F:: g f p$ & This study \\
\hline pTc-P & crRNA-pyrF, $\Delta p y r F:: g f p$ & This study \\
\hline pTc-P-50bp & crRNA-pyrF, $\Delta$ pyrF::gfp with 50 bp homology arms & This study \\
\hline pTc-P-100bp & crRNA-pyrF, $\Delta$ pyrF::gfp with 100 bp homology arms & This study \\
\hline $\mathrm{pTc}-\mathrm{G}$ & crRNA-galK, $\Delta$ galK::Ifp & This study \\
\hline pTc-G2 & crRNA-galK2, $\Delta$ galK::rfp & This study \\
\hline pTc-A & crRNA-araD, $\Delta a r a D:: r p s /$ & This study \\
\hline pTc-A2 & crRNA-araD2, $\Delta a r a D:: r p s l$ & This study \\
\hline pTc-M & crRNA- mutS, $\Delta$ mutS::tcr & This study \\
\hline pTc-L & crRNA-lacZ, $\Delta$ lacZ::aadA & This study \\
\hline pTc-GL & crRNA-galK, $\Delta$ galK::Ifp crRNA-lacZ, $\Delta$ lacZ::aadA & This study \\
\hline pTc-GP & crRNA-galK, $\Delta$ galK::rfp crRNA-pyrF, $\Delta p y r F:: g f p$ & This study \\
\hline pTc-PL & crRNA-lacZ, $\Delta$ lacZ::aadA crRNA-pyrF, $\Delta$ pyrF::gfp & This study \\
\hline pTc-GLP & crRNA-galK, $\Delta$ galK::rfp crRNA-lacZ, $\Delta l a c Z:: a a d A$ crRNA-pyrF, $\Delta$ pyrF::gfp & This study \\
\hline pTc-arrayLP & crRNA-lacZ-pyrF, $\Delta$ lacZ::aadA $\Delta$ pyrF::gfp & This study \\
\hline pTc-arrayPL & crRNA-pyrF-lacZ, $\Delta$ lacZ::aadA $\Delta p y r F:: g f p$ & This study \\
\hline pTc-torS-p103-hem1 & crRNA-torS, storS::p103-hem1 & This study \\
\hline pTc-lacZ-T7RNAP-torS-pT7-hem1 & crRNA-lacZ, $\Delta$ lacZ::T7 RNAP crRNA-torS, $\Delta$ torS::pT7-hem1 & This study \\
\hline pLTT05 & Expressing T7 RNA polymerase and ALA synthase (hem1) & Li et al., 2016 \\
\hline pTD-Cas12a & Expressing codon-optimized FnCas12a (type 2) & This study \\
\hline pTtd-prpC & crRNA-prpC, $\Delta$ prpC & This study \\
\hline pTtd-prpC-PM & crRNA-prpC, prpC with point mutation & This study \\
\hline
\end{tabular}

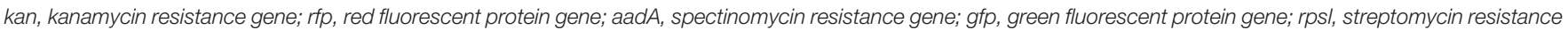

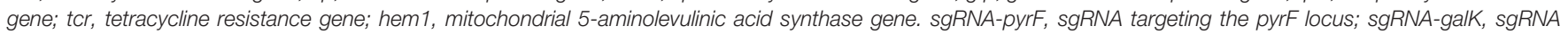

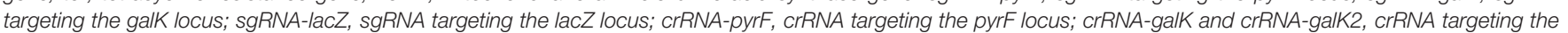

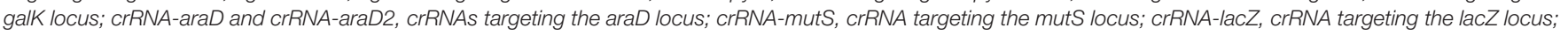

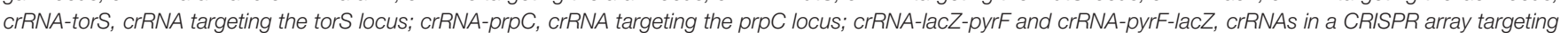

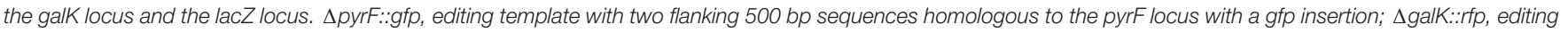

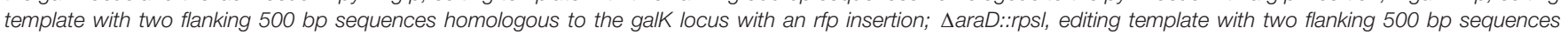

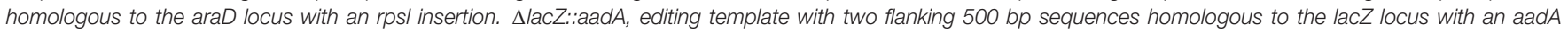

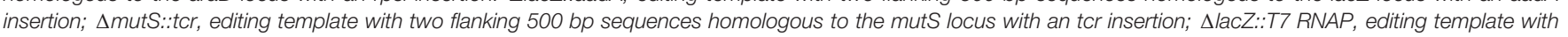

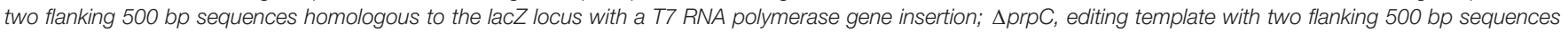
homologous to the prpC locus. p103-hem1, hem1 controlled by the 103 promoter; pT7-hem1, hem1 controlled by the T7 promoter.

the survival chance of cells with intact or deficient twoplasmid systems. It was shown that Cas12a and crRNA were necessary for inducible cell killing (Figure 2B, cases a, b, and e). Furthermore, donor DNA has an important impact on recovery from the double-strand break caused by the CRISPR-Cas12a as the editing template (Figure $\mathbf{2 B}$, cases $\mathbf{c}$ and e). Although $\lambda$-Red was considered to accelerate recombination, more cells recovered from cleavage by Cas12a when $\lambda$-Red was not induced
(Figure 2B, cases $\mathrm{d}$ and e), which was probably due to a reduction of metabolic stress. It was confirmed that the inhibition of Cas12a expression by the addition of glucose prevented cell death caused by the double-strand break. This phenomenon guaranteed the coexistence of the helper plasmid with the Cas12a gene and the donor plasmid with the crRNA. After the necessity of the different components of the two-plasmid system was confirmed, several parameters were adjusted to achieve a high integration 
A

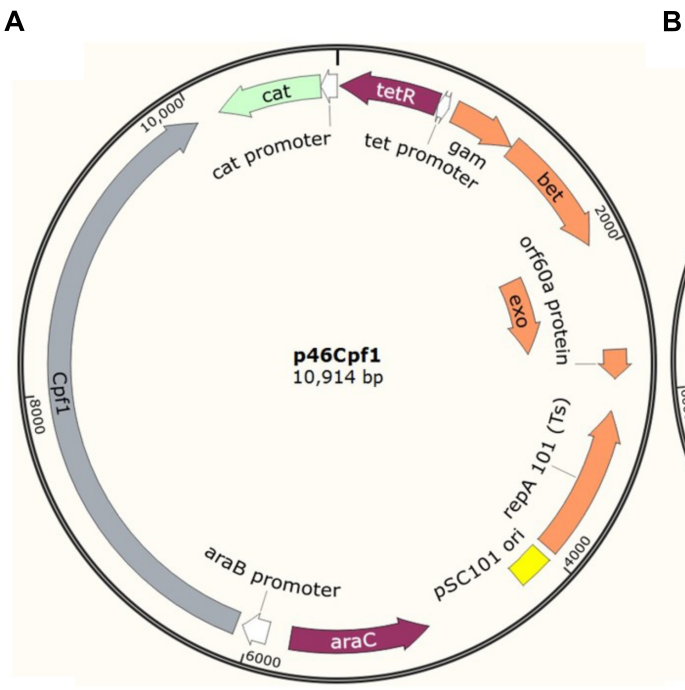

C

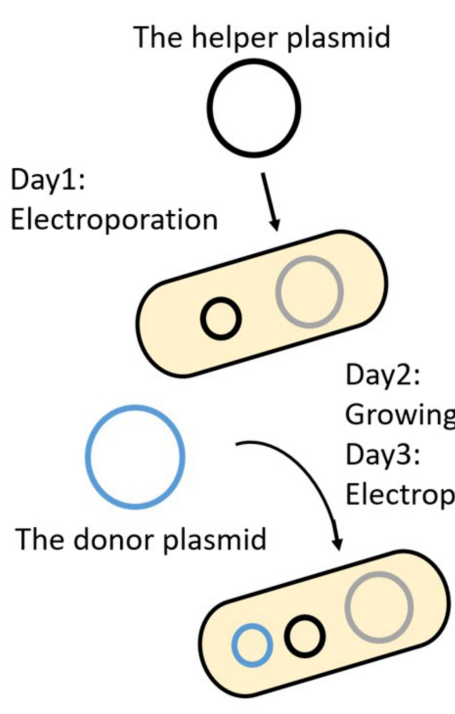

B

Day5:
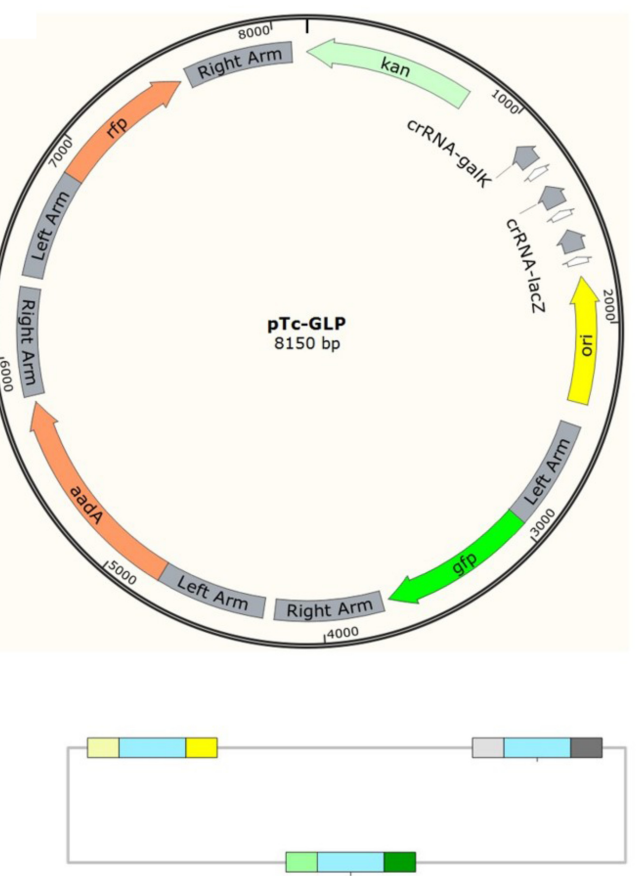

The engineered strain

Day7\&8:

Curing plasmids

Day6:

Screening

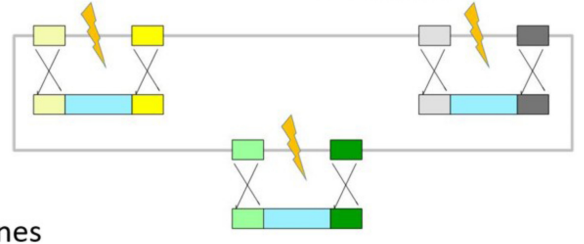

Growing clones

Recombination

FIGURE 1 | Schematic maps of the developed method. (A) A schematic of the helper plasmid p46Cpf1, in which $\lambda$ Red recombinases (Gam, Bet, and Exo) are expressed under the control of $P_{\text {tet }}$, and Cas12a is expressed under the control of $P_{\text {araB }}$. (B) A schematic of the donor plasmid pTc-GLP, which encodes crRNAs constitutively and provides the templates for recombination at three loci (galK, lacZ, and pyrF). (C) General outline of the multiplex gene insertion method. It takes 8 days to construct a modified plasmid-free strain.

efficiency. Also, the $\lambda$-Red requirement was evaluated in the next section.

\section{Optimization of the Two-Plasmid System}

We proposed to introduce the two plasmids into E. coli MG1655 sequentially, and incubate the obtained colonies without induction. After a certain number of cells had amplified, $\lambda$-Red and Cas12a were induced to accelerate recombination and selection. Cultures were spread on plates with L-arabinose to induce the expression of Cas12a consistently. We selected 12 colonies from each plate for PCR genotyping (Supplementary Figure S1). The integration efficiency was defined as the rate of the number of modified colonies to the total number of colonies that had been genotyped. A general outline of this method is shown in Figure 1C.

We tested the recombination system by introducing a gene at a single locus in the E. coli genome. To avoid affecting the growth of the modified cells, five sites with non-essential genes ( $a r a D$, galK, lacZ, mutS, and $p y r F$ ) were selected for the integration of heterologous genes, and crRNAs targeting these genomic sites (Supplementary Table S3) were designed.

Firstly, it was reported that the assistance of $\lambda$-Red was necessary in the genome editing technologies based on CRISPRCas9 (Jiang et al., 2015; Pyne et al., 2015; Bassalo et al., 2016), and the $\lambda$-Red requirement was also evaluated for this strategy. 

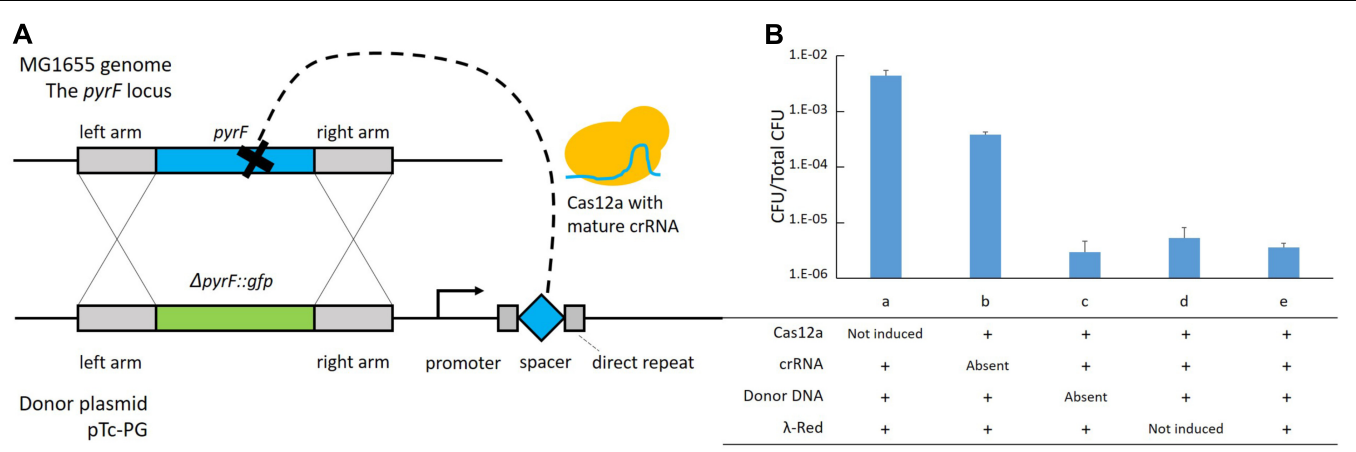

FIGURE 2 | Effects of different components in the two-plasmid system on inducible cell killing. (A) Diagram of the events during genome editing. (B) Effects of Cas12a, targeting crRNA, donor DNA and $\lambda$-Red in the two-plasmid system. The data represent the means \pm standard deviations from three measurements for each experiment.
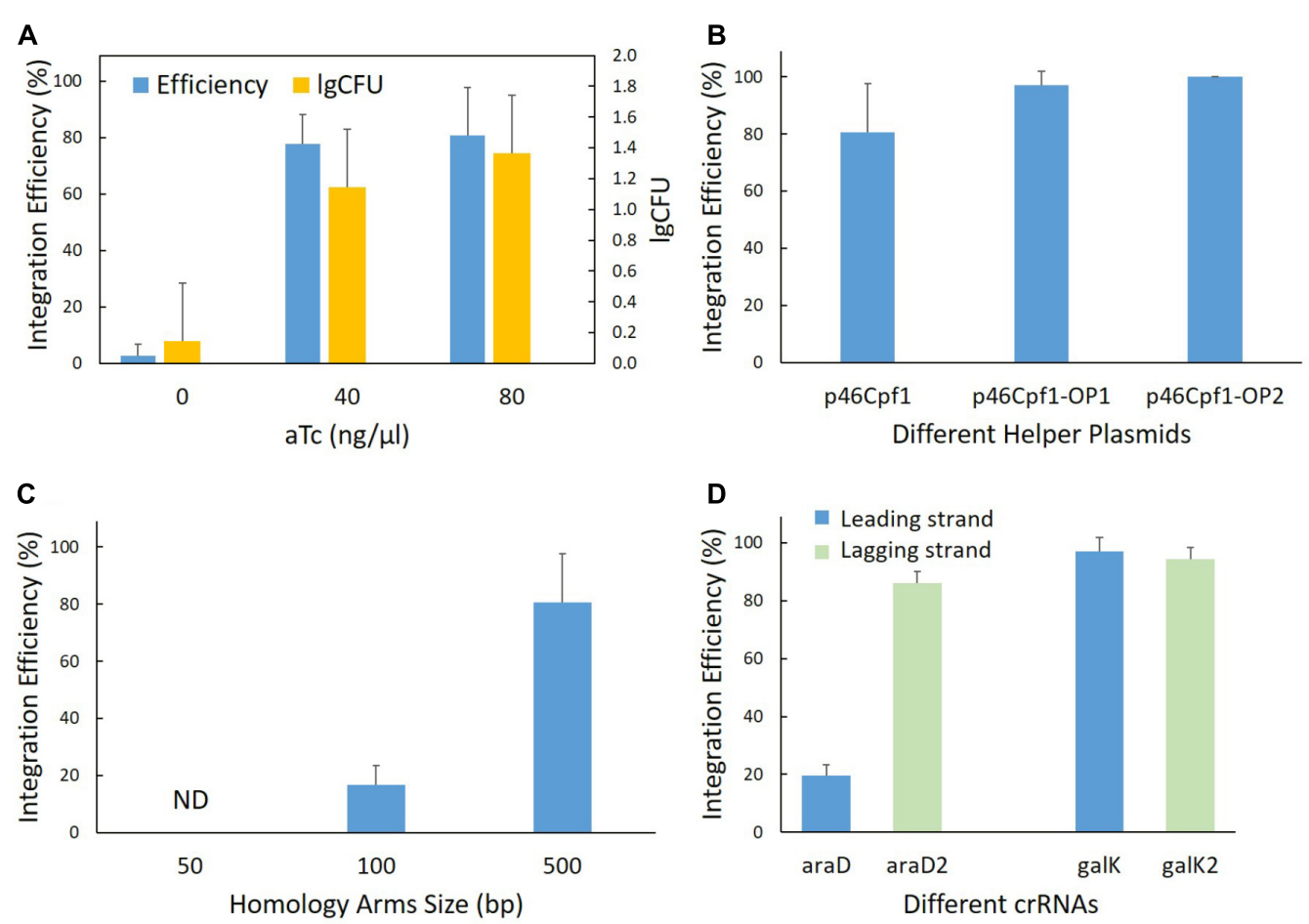

FIGURE 3 | Parameters affecting recombination efficiency. (A) Effect of the $\lambda$-Red machinery. Genomic integration was performed at the pyrF site in both the $\lambda$-Red induced (aTc added) and non-induced (aTc not added) backgrounds. The helper plasmid p46Cpf1 and the donor plasmid pTc-PG were used. CFU stands for colony number of forming units per microliter of culture. (B) Effect of codon optimization of the Cas12a gene. Genomic integration was performed at the pyrF site using different helper plasmids - p46Cpf1 with the original Cas12a (Cpf1) gene, p46Cpf1-OP1 and p46Cpf1-OP2 with codon optimized Cas12a genes. The donor plasmid pTc-PG was used. (C) Effect of homology arm length on integration efficiency. Genomic integration was performed at the pyrF site with different donor plasmids, pTc-P-50bp providing the donor template with 50-bp homology arms, pTc-P-100bp with 100-bp homology arms and pTc-P with 500-bp homology arms. The helper plasmid p46Cpf1 was used. Modified colonies were not detected when using 50 bp homology arms. ND, not detected. (D) Relationship between integration efficiency and different crRNAs. The crRNAs araD and galK target the leading strand in the $E$. coli genome, while the crRNAs araD2 and galK2 target the lagging strand. The helper plasmid p46Cpf1 was used. The data represent the averages of three independent experiments.

In the helper plasmid, the $\lambda$-Red proteins are expressed under the control of an aTc-inducible promoter, $\mathrm{P}_{\text {tet }}$. Therefore, it was possible to regulate $\lambda$-Red production using the inducing agent aTc. The helper plasmid p46Cpf1 and the donor plasmid pTc-P were used to edit the pyrF locus in both the induced and noninduced backgrounds. While the two-plasmid system worked in the induced backgrounds at two different concentrations, almost no modified cells were observed in the non-induced backgrounds (Figure 3A), underlining the necessity of $\lambda$-Red for efficient recombination. Although, from the experimental results, an increase of the aTc concentration from 40 to $80 \mathrm{ng} / \mu \mathrm{l}$ did not have a significant effect on integration efficiency or the amount 
of surviving cells, we chose the aTc concentration of $80 \mathrm{ng} / \mu \mathrm{l}$ in subsequent experiments to ensure the adequate supply of $\lambda$-Red recombinases.

Secondly, we aimed to improve the expression of Cas12a for effective selection. One option was to use a strong promoter or ribosome binding site (RBS) to augment the amount of messenger RNA (mRNA). The Cas12a gene, however, is very large $(\sim 4 \mathrm{~kb})$, which causes a great burden for the cells when it is transcribed at high levels. Thus, codon optimization of the Cas12a gene was conducted to improve the production of mature Cas12a while keeping the mRNA content at the original level. To this end, two different codon optimization strategies were employed. The Cas12a (Cpf1) gene in p46Cpf1-OP1 was optimized using OPTIMIZER (Puigbo et al., 2007), whereas in p46Cpf1-OP2, another tool, JCat (Grote et al., 2005) was utilized (Supplementary Table S3). The same donor plasmid, Tc$\mathrm{P}$ (Table 1), was harnessed for recombination at the pyrF site, while three different donor plasmids were tested that supplied the $\lambda$-Red proteins and Cas12a in different quantities. The results are shown in Figure 3B and Supplementary Figure S2. Although the results were not statistically significant to prove a more efficient recombination or selection assisted by $\mathrm{p} 46 \mathrm{Cpf} 1-\mathrm{OP} 1$ or $\mathrm{p} 46 \mathrm{Cpf} 1$ $\mathrm{OP} 2$, an increased average integration efficiency was observed after the Cas12 gene was codon optimized. We presumed that production enhancement of mature Cas12a had a positive impact on the recombination assays.

Thirdly, we tested different lengths of the homology arms. At the $p y r F$ site, recombination templates with $50 \mathrm{bp}$ (pTc-P-50bp), $100 \mathrm{bp}$ (pTc-P-100bp) and $500 \mathrm{bp}$ (pTc-P) homology arms were used. As a result, $50 \mathrm{bp}$ homology arms were insufficient for recombination, and integration efficiency increased dramatically when the homology arms were elongated from $100 \mathrm{bp}$ to $500 \mathrm{bp}$ (Figure 3C).

Finally, the effect of different crRNAs was explored. We designed two crRNAs at each site for araD and galK, respectively. The plasmids pTc-G and pTc-A expressed crRNAs targeting the leading strand in the E. coli genome, while those expressed by pTc-G2 and pTc-A2 targeted the lagging strand. It was interesting that the two crRNAs targeting the araD site had markedly different appearance. At the galK site, however, the results of using different crRNAs were similar (Figure 3D). There was not enough evidence to draw a conclusion on effects of crRNAs targeting different strands. Nevertheless, it is inferred better to design at least two crRNAs for a locus in order to ensure a functional one.

\section{Performing Gene Insertion at a Single Locus}

The 5 donor plasmids (Tc-A2, Tc-G, Tc-L, Tc-M, and Tc-P), providing a series of paired crRNAs and donor DNAs, were combined in the recombination assays with the helper plasmid p46Cpf1-OP2. In each round of experiment, 12 colonies were genotyped by PCR, and one of the resulting modified clones was verified by DNA sequencing to confirm the integration of the heterologous gene (Supplementary Figure S3). As shown in Figure 4, the integration efficiency was almost $100 \%$ at each site.

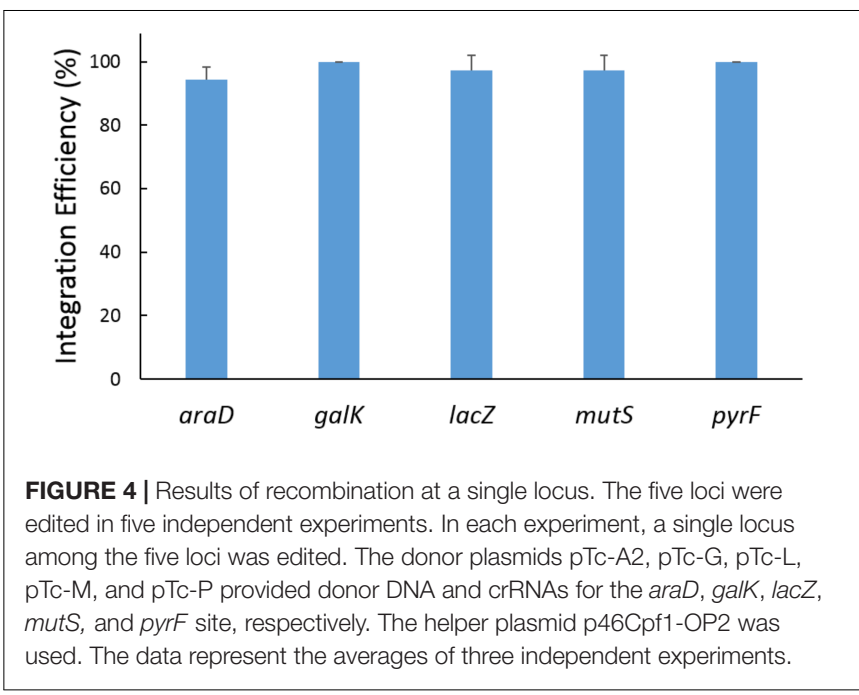

The five loci (araD, galK, lacZ, mutS, and pyrF) are scattered in different places on the chromosome, indicating that the developed method is applicable on the whole genome.

\section{Simultaneous Recombination at Multiple Loci}

We next investigated if this method can be used to simultaneously insert genes at multiple loci of the E. coli chromosome.

Firstly, we attempted to insert genes at two sites simultaneously. Different combination of two cRNAs against the three selected target sites ( $g a l K$, lac $Z$, and $p y r F)$ were tested. As shown in Figure 5A, the introduction of both heterologous genes was confirmed in more than $40 \%$ of the colonies when p46Cpf1-OP2 was utilized as the helper plasmid.

Subsequently, simultaneous insertion in all the three loci was conducted using the donor plasmid pTc-GLP and the helper plasmid p46Cpf1-OP2 (Figure 5A and Supplementary Figure S4). As we had anticipated, the integration efficiency decreased dramatically with the increase in the number of simultaneous insertions. Nevertheless, simultaneous gene insertion into three sites was achieved with an acceptable efficiency. One colony with all three desired modifications appeared on average among every five colonies, meaning that researchers should be able to obtain the desired strain through limited work spent on PCR genotyping.

Furthermore, several crRNAs can be arranged in a CRISPR array that can be processed by Cas12a itself (Fonfara et al., 2016). This feature of the CRISPR-Cas $12 \mathrm{a}$ system makes it convenient for the expression of crRNAs targeting multiple loci. In order to compare different ways of supplying crRNAs, pTc-arrayLP and pTc-arrayPL were constructed, with crRNAs expressed in a CRISPR array in different orders. By contrast, in pTc-PL the crRNAs were expressed separately. Recombination assays were conducted using these donor plasmids and the helper plasmid p46Cpf1-OP2.Importantly, supplying crRNAs in a CRISPR array did not reduce the integration efficiency (Figure 5B). 

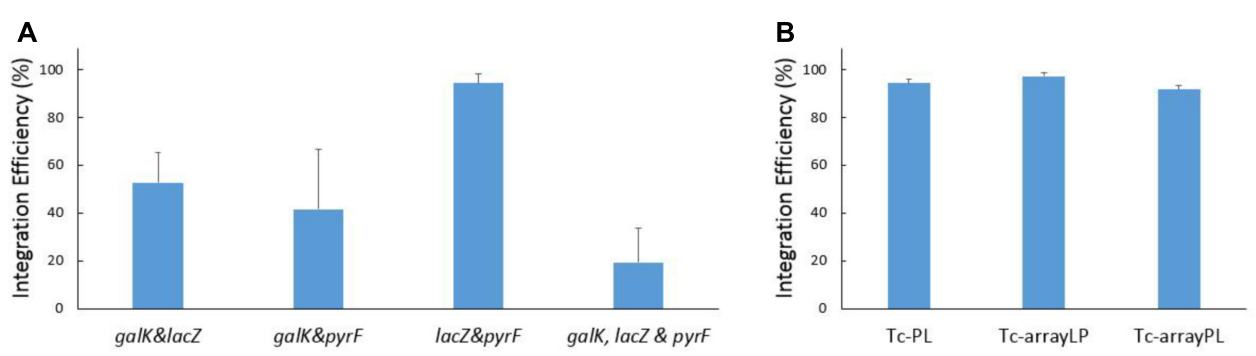

FIGURE 5 | Results of simultaneous recombination at multiple sites. (A) Efficiency of simultaneous integration at two and three sites. The helper plasmid p46Cpf1-OP2 was used. Different combination of two cRNAs against the three selected target sites (galK, lacZ, and pyrF) were used in the recombination experiment. The donor plasmids pTc-GL was used for recombination at the galK and lacZ sites; pTc-GP, galK and pyrF sites; pTc-PL, lacZ, and pyrF sites. And the donor plasmid pTc-GLP was used for simultaneous recombination at all the three sites (galK, lacZ, and pyrF). (B) Effect of different ways of supplying the crRNAs. The donor plasmid pTc-PL expresses two crRNAs separately, while the donor plasmids pTc-arrayLP and pTc-arrayPL express crRNAs arranged in a CRISPR array. The helper plasmid p46Cpf1-OP2 was used. The data represent the averages of three independent experiments.

\section{Comparing the Two-Plasmid Systems Based on CRISPR-Cas12a and CRISPR-Cas9}

To explore the differences of the efficiency of Cas12a and Cas9 in recombination and counterselection, both CRISPR-Cas systems were employed to build helper plasmids and donor plasmids. Recombination at a single locus, two loci and three loci was tested. As shown in Figure 6, the systems based on Cas9 and codon-optimized Cas12a had similar performance.

Assisted by CRISPR-Cas12a or CRISPR-Cas9, the integration efficiency at a single locus was almost 100\% (Figures 4, 6). However, at multiple separate loci, it might decreased significantly. For example, at the galK and pyrF loci, the integration efficiency was about 40\% (Figure 5A) and it dropped to about $20 \%$ when performing recombination simultaneously at 3 loci (Figure 6). It was reported that cells escaping from Cas9 cleavage might carry a defective CRISPR system (Cui and Bikard, 2016). The similar performance of CRISPR-Cas12a and CRISPR-Cas9 in the two-plasmid system convinced us that cells could also escape from Cas12a cleavage due to the deficiency in the CRISPR system. When double-strand breaks were introduced to multiple separate loci in the chromosome at the same time, it might be difficult to repair all the breaks through homologous recombination. Less cells survived through recombination between the chromosome and the donor DNA, while more cells carried a defective CRISPR system, leading to the dramatic decrease in integration efficiency.

\section{Construction of Recombinant E. coli Strains for the Production of ALA}

To demonstrate the practical application of this gene-insertion method, we constructed recombinant E. coli strains for the production of ALA, an industrially useful chemical. In the past, we constructed a series of strains for the production of ALA which carry the codon-optimized mitochondrial 5aminolevulinic acid synthase (EC: 2.3.1.37, hem1) gene on plasmids (Li et al., 2016). Although expressing genes from highcopy-number plasmids enables high output, episomal plasmids are sometimes unstable (Ganusov and Brilkov, 2002) and require

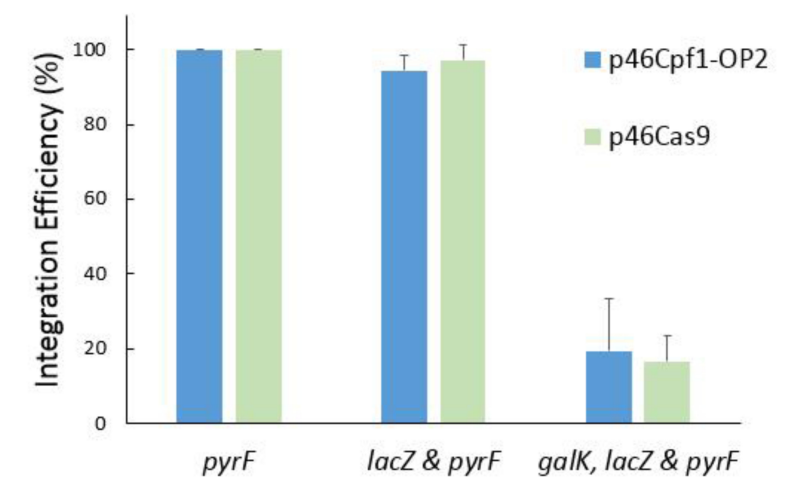

FIGURE 6 | Recombination efficiency of different CRISPR systems. The helper plasmid p46Cpf1-OP2 was combined with the donor plasmids pTc-P, pTc-PL, and pTc-GLP to perform simultaneous modifications at a single locus (pyrF), two loci (lacZ and pyrF) and three loci (galK, lacZ, and pyrF), respectively. For recombination based on CRISPR-Cas9, p46Cas9, pTs-P, pTs-PL, and pTs-GLP were used. The data represent the averages of three independent experiments.

the addition of antibiotics during fermentation (Godwin and Slater, 1979), which makes chromosomal integration of metabolic pathways a promising alternative (Englaender et al., 2017). In this study, we achieved to integrate the hem 1 gene into the E. coli chromosome using the developed gene inserting method.

To obtain a high-yielding recombinant strain, we selected two promoters to control the hem 1 gene: the constitutive 103 promoter $\left(\mathrm{P}_{103}\right)$ and the $\mathrm{T} 7$ promoter $\left(\mathrm{P}_{\mathrm{T} 7}\right)$. The p103-hem1 cassette $(\sim 1.8 \mathrm{~kb}$, Supplementary Table S5) was integrated into the torS site to construct the strain MG1655AX01 (Table 1 and Figure 7A). The strain MG1655AX02 (Table 1 and Figure 7A) was obtained by simultaneously integrating the T7 RNAP cassette ( $2.6 \mathrm{~kb}$, Supplementary Table S5) into the lacZ site and the pT7-hem 1 cassette ( $\sim 2.0 \mathrm{~kb}$, Supplementary Table S5) into the torS site. In MG1655AX02, T7 RNAP was under control of the native lac promoter $\left(\mathrm{P}_{\text {lac }}\right)$, which is isopropyl- $\beta$-D-thiogalactoside (IPTG)-inducible. We introduced the plasmid pLTT05 into MG1655 to obtain the strain MG1655AX03 (Table 1), in which 


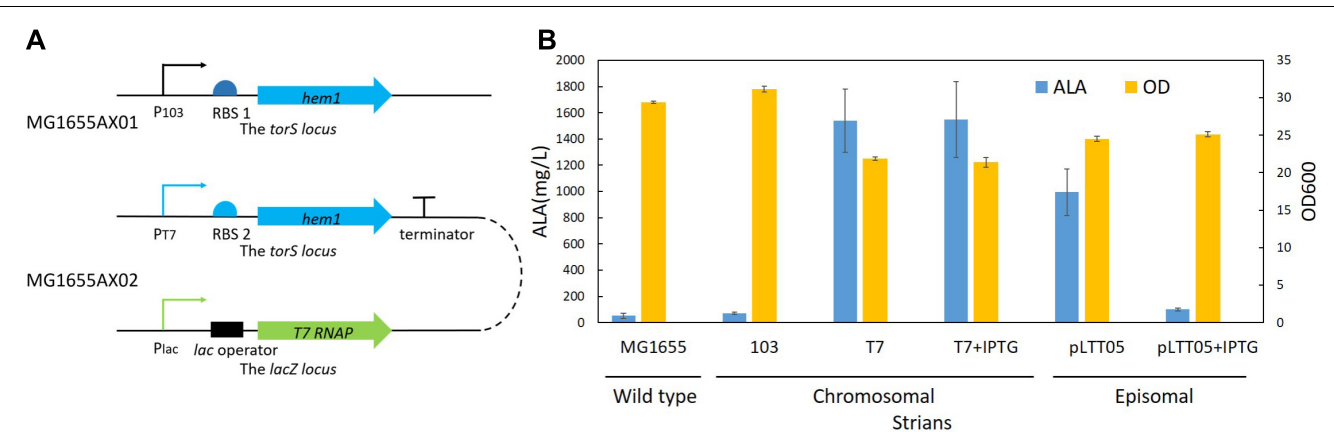

FIGURE 7 | ALA production by different strains. (A) A schematic of the genetically modified MG1655 strains. (B) Results of ALA production. 103 stands for the strain MG1655AX01 which carries a chromosomally integrated hem1 gene controlled by the 103 promoter; T7 stands for the strain MG1655AX02 which carries a chromosomally integrated hem1 gene controlled by the T7 promoter and a chromosomally integrated T7 RNA polymerase gene controlled by the native lac promoter; pLTT05 stands for the strain MG1655AX03 which harbors the plasmid pLTT05. pT7 + IPTG and pLTT05 + IPTG denote that IPTG was added during the fermentation of the corresponding strains.

the hem1 gene was controlled by a T7lac promotor and T7 RNAP was expressed constitutively. These strains were used for fermentation. The best average yield of the recombinant strain MG1655AX02 was $1.55 \pm 0.29 \mathrm{~g} / \mathrm{L}$, a performance better than that of MG1655AX03 with an episomal hem1 gene (Figure 7B), which was probably the result of the usage of a strong RBS. Intriguingly, MG1655AX02 had similar performance in induced and non-induced conditions while MG1655AX03 produced much less ALA when induced by IPTG. These results implied that the proteins leaking from the IPTG-inducible promoters $\left(\mathrm{P}_{\text {lac }}\right.$ or $\left.\mathrm{P}_{\text {T7lac }}\right)$ might be enough for efficient production of ALA and that excessive expression of T7 RNA polymerase or ALA synthase was a burden for bacteria. Although we made sure that nearby promoters in the upstream of hem 1 or T7RNAP would not influence the protein expression by positioning them in the opposite direction, it was noteworthy that random sequences could somehow serve as active promoters. Thus, terminators should be added in the upstream of these genes to insulate them from outside influence.

\section{Editing the Genome of Halomonas bluephagenesis}

Recently, a method based on CRISPR-Cas9 for editing the genome of the extremophilic Halomonas spp. was reported (Qin et al., 2018). Notwithstanding, CRISPR-Cas12a can be used when there are no appropriate targets for Cas9, because they recognize different PAM regions. To test the potential of CRISPR-Cas12a in editing the genome of different bacterial species, we built another two-plasmid system for genome editing in $H$. bluephagenesis, comprising the helper plasmid pTD-Cas12a and a donor plasmid, for example, pTtd-prpC (Table 1). Similar strategies as reported by Qin et al. (2018) were exploited to perform the deletion of prpC in the chromosome of $H$. bluephagenesis. pTtd-prpC was used to delete the prpC gene, and pTtd-prpC-PM was used to introduce a point mutation into the PAM sequence in the target of crRNA-prpC, generating a premature stop codon (Supplementary Figure S5). After genotyping of the resulting colonies (Supplementary Figure S5), modified cells were sequenced to confirm the mutations. Thus, it was demonstrated that the CRISPR-Cas12a system can be used for genome editing in a non-model species of bacteria, the extremophilic H. bluephagenesis.

\section{DISCUSSION}

In this study, we developed a fast and convenient genome editing method based on the CRISPR-Cas12a system, which can perform gene insertions at multiple loci simultaneously (Table 2). Our system is capable of editing two genes simultaneously with high efficiency (more than 40\%), and three genes simultaneously with lower, but detectable efficiency (about 20\%). Compared with Cas9, the smaller size of Cas12a enabled the use of smaller plasmids, and therefore allowed easier manipulation (plasmid construction, electroporation, etc.). The T-rich PAM of Cas12a, which differs from the G-rich PAM of Cas9, should expand the scope of target sites in the organism's genome. Similar to published genome editing technology based on CRISPRCas9, our system can perform rapid gene insertion in a single recombination step, whereas other scarless genome editing methods involving I-SceI (Pósfai et al., 1999; Yu et al., 2008; Yang et al., 2014) take two steps to obtain a modified strain. The CRISPR-Cas9 technology (Table 2) is able to perform multiple gene deletions at one time. However, its ability to integrate multiple genes into the chromosome has not been verified (Jiang et al., 2015; Li et al., 2015). Although another genome editing technology based on CRISPR-Cas9, the no-SCAR method (Reisch and Prather, 2015), achieves multiple genomic modifications iteratively, it takes more time than our system when performing modifications on multiple loci. Using the noSCAR method, it takes 11 days to obtain a plasmid-free strain with two mutations and 14 days for a strain with three, while we were able to construct a strain with three mutations in 8 days (Table 2).

Several parameters were adjusted to improve the twoplasmid system, including the usage of codon-optimized Cas12a. Also, by arranging crRNAs separately or in a CRISPR array, 
TABLE 2 | Comparisons of genome editing methods assisted by CRISPR-Cas system.

\begin{tabular}{|c|c|c|c|c|c|}
\hline Comparison & Method & This study & $\begin{array}{l}\text { Cas9-assisted method } \\
\text { (Li et al., 2015) }\end{array}$ & $\begin{array}{l}\text { Cas12a-assisted method } \\
\text { (Yan et al., 2017) }\end{array}$ & $\begin{array}{l}\text { NO SCAR (Reisch and } \\
\text { Prather, 2015) }\end{array}$ \\
\hline \multirow[t]{2}{*}{ Component } & Cas gene & $\begin{array}{l}\text { Codon-optimized } \\
\text { FnCas } 12 a\end{array}$ & SpCas9 & FnCas $12 a$ & SpCas9 \\
\hline & Donor DNA & Circular (plasmids) & Linear (PCR products) & $\begin{array}{l}\text { Linear (PCR products or } \\
\text { oligonucleotides) }\end{array}$ & $\begin{array}{l}\text { Linear (PCR products or } \\
\text { oligonucleotides) }\end{array}$ \\
\hline \multirow[t]{2}{*}{ Editing efficiency } & At a single locus & Nearly $100 \%$ & Nearly $100 \%$ & More than 50\% & $85 \sim 100 \%$ \\
\hline & At multiple loci & $\begin{array}{l}\text { About } 20 \% \text { for } 3 \text { gene } \\
\text { insertions }\end{array}$ & $\begin{array}{l}\text { About } 20 \% \text { for } 3 \text { point } \\
\text { mutations }\end{array}$ & Not tested & Not tested \\
\hline \multirow[t]{3}{*}{ Time } & 1 mutation & 8 days & 7 days & 7 days & 8 days \\
\hline & 2 mutations & 8 days & 13 days & 13 days & 11 days \\
\hline & 3 mutations & 8 days & 19 days & 19 days & 14 days \\
\hline
\end{tabular}

different ways to supply crRNAs were explored and showed similar performance. Differences in the recombination and counterselection ability between the systems based on Cas12a and Cas9 were explored and it was proved the system based on Cas 9 performed similarly to those based on codon-optimized Cas12a. In addition, the loss of protospacer between direct repeat sequences in crRNA was observed, and novel strategies for supplying guide RNAs have a potential to address this limitation (Gao and Zhao, 2014; Port and Bullock, 2016; Xu et al., 2017) and to improve this genome editing method.

It was recently reported that CRISPR-Cas12a has indiscriminate single-stranded DNase activity (Chen et al., 2018). Since we used circular DNAs (sequences as part of the donor plasmid) as donor templates, such single-stranded DNase activity should have little impact on the recombination events, ensuring the success of multiplex genome engineering of up to 3 loci. We speculated that it would be necessary to avoid using linear DNAs (PCR products or oligonucleotides) as editing templates to increase the editing efficiency.

The $\lambda$-Red recombinase complex, comprising Gam, Bet and Exo, is necessary to promote recombination (Datsenko and Wanner, 2000; Jiang et al., 2015). Exo is an exonuclease which digests double-stranded DNA (dsDNA) from $5^{\prime}$ to $3^{\prime}$, generating single-stranded DNA (ssDNA). Bet is an ssDNA binding protein (Murphy, 1998; Zhang et al., 1998). The $\lambda$-Red component Gam is able to block the RecBCD complex to protect the DNA template from digestion (Murphy, 1991; Marsiæ et al., 1993). It is believed that the generated ssDNA acts as the template during recombination (Stahl et al., 1997). However, instead of linear DNAs, we used circular DNAs (donor plasmids) as editing templates, which makes it challenging to process the circular templates into ssDNA. What's more, CRISPR-Cas12a has indiscriminate single-stranded DNase activity. Considering these features of the system, we deduced that an altered recombination mechanism must mediate the functioning of our two-plasmid system and that the double-stand breaks (DSBs) caused by the CRISPR system had a vital role of triggering the recombination events other than selection. Previous research based on the CRISPR-Cas9 system showed that when using 50-bp homology arms and PCR products as templates, the editing efficiency of $1 \mathrm{~kb}$ insertions is nearly 50\% (Li et al., 2015). However, when using 50-bp homology arms and circular templates in our system, no modified cells were detected (Figure 3C). The hypothesis of different recombination mechanisms is therefore a reasonable explanation for this phenomenon.

To demonstrate the practical application of this multiplex gene-insertion method, we constructed a recombinant E. coli producing an industrially useful chemical, ALA, at high yield. Moreover, a similar two-plasmid system was built to edit the genome of the extremophile $H$. bluephagenesis which indicates the promising potential of the CRISPR-Cas12a system in assisting genome editing in different bacterial species, including nonmodel organisms.

In Supplementary Table S6, we summarized the abovementioned recombination assays. When developing the twoplasmid system, the culture of each assay was spread onto two plates - one with L-arabinose to keep the expression of Cas protein and the other with glucose to inhibit the expression. The rate of colony number on the L-arabinose plate to that on the glucose plate $\left(\mathrm{CFU}_{\text {arabinose }} / \mathrm{CFU}_{\text {glucose }}\right)$ was between 0.1 and 1.0 (Supplementary Table S6). However, when coupling the recombination with electroporation, the survival chance of cells with intact two-plasmid systems was much lower (Figure 2B, column e). Introducing the donor plasmid into cells beforehand was then a considerable approach to accelerate genome editing.

In summary, we demonstrated that the developed method enables rapid and efficient gene insertions at up to three genomic loci simultaneously in a "markerless" and "scarless" manner. We obtained a plasmid-free strain with three heterologous genes integrated into multiple loci of the chromosome in just 8 days. This method should therefore expedite multiplex genome editing in E. coli and benefit further engineering and synthetic biology studies.

\section{MATERIALS AND METHODS}

\section{Bacterial Strains and Plasmids}

All strains and plasmids used in this study are listed in Table $\mathbf{1}$ and Supplementary Table S1. E. coli strain Trans1-T1 (TransGen Biotech Co., Ltd, China) was used as the host strain for plasmid construction, and E. coli strain MG1655 (CGSC 6300) 
was used as targets for genome engineering. Primers used for plasmid construction are listed in Supplementary Table S2. Sequences encoding the synthetic guide RNA (sgRNA) (Jinek et al., 2012), crRNAs, the spCas 9 gene, the wild-type FnCas12a gene (Zetsche et al., 2015) and the two FnCas12a gene variants codon-optimized were synthesized by Qinglan Biotech (Suzhou, China) (Supplementary Table S3). The selected targets for the CRISPR-Cas system in the E. coli genome are listed in Supplementary Table S3. After DNA amplification, restriction enzyme digestion, ligation and other standard molecular cloning standard procedures were performed to construct the plasmids. We used DNA purification and plasmid isolation kits from Biomed (Beijing, China). The Q5 polymerase was purchased from New England Biolabs (Beijing, China). The restriction enzymes and ligation kits were purchased from Thermo Fisher Scientific (China).

\section{Testing Effects of Components in the Two-Plasmid System}

MG1655 harboring p46Cpf1 was incubated with the corresponding inducer/inhibitor (aTc and L-arabinose/glucose) and then processed into competent cells (Sharan et al., 2009). We spread $50 \mu \mathrm{L}$ of electrocompetent cells on LB plates to calculate total CFU. Next, $100 \mathrm{ng}$ of different plasmids was introduced into $50 \mu \mathrm{L}$ of electrocompetent cells. After 1-h incubation at $30^{\circ} \mathrm{C}$ and $200 \mathrm{rpm}$, the cells were spread on LB plates with chloramphenicol, kanamycin and L-arabinose/glucose. CFUs were calculated after 1-day incubation at $30^{\circ} \mathrm{C}$. The ratio of transformed CFU to total CFU is shown in Figure 2B. In case a, Cas12a (Cpf1) was not induced due to absence of L-arabinose and presence of glucose; in case b, c, and e, both Cas12a and $\lambda$-Red were induced due to presence of aTc and L-arabinose; in case $\mathrm{d}, \lambda$-Red was not induced due to absence of aTc. In case a, d, and e, the helper plasmid pTc-P was used to provide the crRNA and the donor DNA; in case b, the helper plasmid pTs-P was used to provide the donor DNA while the crRNA in CRISP-Cas12a system was absent; in case $c$, the plasmid pcrRNA-P was used to provide the crRNA in CRISPR-Cpf1 system while the donor DNA was absent.

\section{Recombination Assisted by $\lambda$-Red and the CRISPR-Cas System}

A general outline of this method is shown in Figure 1C.

Day 1: Grow MG1655 in LB at $37^{\circ} \mathrm{C}$ overnight. Next morning, add $0.2 \mathrm{~mL}$ of the culture to $20 \mathrm{ml}$ of $\mathrm{LB}$ in a $100-\mathrm{mL}$ shake flask and grow at $37^{\circ} \mathrm{C}$ to an $\mathrm{OD}_{600}$ of $0.6-0.8$. Centrifuge the culture at $4,000 \mathrm{~g}$ for $5 \mathrm{~min}$ at $4^{\circ} \mathrm{C}$. Wash the cell pellet with $20 \mathrm{~mL}$ of ice-cold water once and then resuspended in $1 \mathrm{~mL}$ of ice cold water and transfer to a $1.5-\mathrm{mL}$ tube. Centrifuge at $4,000 \mathrm{~g}$ for $2 \mathrm{~min}$ at $4^{\circ} \mathrm{C}$. Wash the cells two more times with $1 \mathrm{~mL}$ of ice-cold $10 \%(\mathrm{v} / \mathrm{v})$ glycerol. Resuspend the cell pellet in ice-cold $10 \%(\mathrm{v} / \mathrm{v})$ glycerol in a final volume of $1 \mathrm{~mL}$. Mix about $100 \mathrm{ng}$ of the helper plasmid with $50 \mu \mathrm{L}$ of electrocompetent cells then transfer into a 2-mm Gene Pulser cuvette (Bio-Rad, United States). Introduce the helper plasmid into the cells by electroporation at $1.8 \mathrm{kV}$. After electroporation, add $1 \mathrm{ml}$ of LB and transfer the cells to a $1.5-\mathrm{mL}$ tube. Incubate the cells at $30^{\circ} \mathrm{C}$ for $1 \mathrm{~h}$. Plate $100 \mu \mathrm{L}$ of the cell suspension onto an LB plate with $12.5 \mu \mathrm{g} / \mathrm{mL}$ chloramphenicol and incubate at $30^{\circ} \mathrm{C} 20-22 \mathrm{~h}$. (Tips: Chemical transformation is feasible as well.)

Day 2: Pick an individual colony and grow in LB with $12.5 \mu \mathrm{g} / \mathrm{mL}$ chloramphenicol at $30^{\circ} \mathrm{C}$ and $200 \mathrm{rpm}$ overnight.

Day 3: Add $0.2 \mathrm{~mL}$ of the culture of the intermediate strain to $20 \mathrm{~mL}$ of LB with $12.5 \mu \mathrm{g} / \mathrm{mL}$ chloramphenicol and $20 \mathrm{~g} / \mathrm{mL}$ glucose (to inhibit transcription from the ParaB promoter) in a $100-\mathrm{mL}$ shake flask and grow at $30^{\circ} \mathrm{C}$ to an $\mathrm{OD}_{600}$ of $0.6-$ 0.8 . Process the intermediate strain into competent cells (same procedure as above). Introduce about $100 \mathrm{ng}$ of the donor plasmid into the cells via electroporation in a 2-mm Gene Pulser cuvette (Bio-Rad) at $1.8 \mathrm{kV}$, after which add $1 \mathrm{~mL}$ LB liquid medium with $20 \mathrm{mg} / \mathrm{mL}$ glucose to the electroporated cells. Regenerate at $30^{\circ} \mathrm{C}$ for $1 \mathrm{~h}$ and plate $100 \mu \mathrm{L}$ of the cell suspension onto an LB plate with $12.5 \mu \mathrm{g} / \mathrm{mL}$ chloramphenicol, $50 \mu \mathrm{g} / \mathrm{mL}$ kanamycin and $20 \mathrm{mg} / \mathrm{mL}$ glucose and incubate at $30^{\circ} \mathrm{C}$ for 20-22 h. (Tips: Chemical transformation is feasible as well.)

Day 4: Pick an individual colony and grow in LB with $12.5 \mu \mathrm{g} / \mathrm{mL}$ chloramphenicol, $50 \mu \mathrm{g} / \mathrm{mL}$ kanamycin and $20 \mathrm{mg} / \mathrm{mL}$ glucose at $30^{\circ} \mathrm{C}$ and $200 \mathrm{rpm}$ overnight.

Day 5: Add $10 \mu \mathrm{L}$ of the resulting overnight seed culture to a culture tube containing $1 \mathrm{~mL}$ LB medium with $50 \mu \mathrm{g} / \mathrm{mL}$ kanamycin and $12.5 \mu \mathrm{g} / \mathrm{mL}$ chloramphenicol. Cultivate at $30^{\circ} \mathrm{C}$ and $200 \mathrm{rpm}$ for $6 \mathrm{~h}$, then add $5 \mathrm{mg} / \mathrm{mL}$ L-arabinose and $80 \mathrm{ng} / \mathrm{mL}$ aTc to the mixture. After a further $2 \mathrm{~h}$ of incubation, spread a serial dilution of the harvested culture $(100,10$, and $1 \mu \mathrm{L}$ as well as $0.1 \mu \mathrm{L}$ of the culture) on LB plates supplemented with $5 \mathrm{mg} / \mathrm{mL}$ L-arabinose, $50 \mu \mathrm{g} / \mathrm{mL}$ kanamycin and $12.5 \mu \mathrm{g} / \mathrm{mL}$ chloramphenicol. (Tips: It is recommended that inducers be added when the turbidity of the culture is visible to the naked eye. In case the bacteria grow slowly, incubate the culture over night before spreading it on plates.)

Day 6: After overnight incubation at $30^{\circ} \mathrm{C}$, confirm the corresponding strains by PCR genotyping.

\section{PCR Genotyping}

PCR genotyping was carried out to distinguish wild-type cells from those with the desired modifications. The corresponding primers are listed in Supplementary Table S4. Hotstart Taq polymerase, which does not possess the $3^{\prime}$ to $5^{\prime}$ exonuclease activity was purchased from TransGen Biotech Co., Ltd., China. Gene insertions were confirmed by PCR amplification using a forward primer targeting a sequence upstream of the genomic locus (at a distance of more than $500 \mathrm{bp}$ from the transcriptioninitiation site) and a reverse primer binding the inserted gene. In order to detect wild-type cells, one primer of the pair was designed to bind the genomic sequence which should disappear after recombination. Twelve colonies were genotyped in each round of experiment. The schematic diagrams were provided in Supplementary Figure S1. In some cases, both genotypes were detected in a single colony (Supplementary Figures S2B,C, arrows), which means that such a colony was composed of both wild-type and modified cells. A mutant colony was confirmed as successfully modified only if no wild-type cells were detected. The integration efficiency stands for the ratio of 
successfully modified colony number to total colony number in the PCR genotyping test.

\section{Plasmid Curing}

The confirmed colonies were picked and grown in $2 \mathrm{~mL}$ of $\mathrm{LB}$ at $42^{\circ} \mathrm{C}$ and $200 \mathrm{rpm}$ overnight. Next morning, the culture was diluted and spread onto LB plates. After $12 \mathrm{~h}$ incubation at $37^{\circ} \mathrm{C}, 24$ resulting colonies were picked and each of them was inoculated onto three distinct plates - an LB plate supplemented with $50 \mu \mathrm{g} / \mathrm{mL}$ kanamycin, an LB plate supplemented with $12.5 \mu \mathrm{g} / \mathrm{mL}$ chloramphenicol and a further LB plate without antibiotics. The colonies sensitive to both antibiotics were confirmed as plasmid-free.

\section{Construction of the Recombinant E. coli Strain and Production of ALA}

The plasmids p46Cpf1-OP2 and pTc-torS-p103-hem1 were used to construct the recombinant $E$. coli MG1655AX01 with the hem1 gene controlled by $\mathrm{P}_{103}$ inserted into the torS site. The plasmids p46Cpf1-OP2 and pTc-lacZ-T7RNAPtorS-pT7-hem1 were used to construct the recombinant E. coli MG1655AX02 with the hem1 gene controlled by $\mathrm{P}_{\mathrm{T} 7}$ inserted into the torS site and the T7 RNA polymerase gene into the lac $Z$ site. At the torS site, the primer pair AX069/AX070 (Supplementary Table S4) was used in genotyping PCR to verify the modified cells, while the primer pair AX067/AX068 (Supplementary Table S4) was used to verify wild-type cells.

The tested strains were incubated in $20 \mathrm{~mL}$ of $\mathrm{LB}$ medium at $37^{\circ} \mathrm{C}$ and $200 \mathrm{rpm}$ overnight to form seed cultures. $1 \mathrm{~mL}$ of the seed culture was inoculated into a $50-\mathrm{mL}$ shake flask containing $20 \mathrm{~mL}$ of $\mathrm{pH}$-adjusted $\mathrm{LB}$ medium $(10 \mathrm{~g} / \mathrm{L}$ tryptone, $5 \mathrm{~g} / \mathrm{L}$ yeast extract, $83.4 \mathrm{mM} \mathrm{K} \mathrm{HPO}_{4} \bullet 3 \mathrm{H}_{2} \mathrm{O}, 216.6 \mathrm{mM} \mathrm{KH} \mathrm{PO}_{4}$, $3.0 \mathrm{~g} / \mathrm{L}$ glycine and $6.0 \mathrm{~g} / \mathrm{L}$ succinic acid). Where appropriate, $2 \mathrm{mM}$ isopropyl- $\beta$-D-thiogalactoside (IPTG) was added at the beginning of the fermentation. The fermentation was conducted at $30^{\circ} \mathrm{C}$ and $200 \mathrm{rpm}$. After $18 \mathrm{~h}$ of incubation, an additional $10.0 \mathrm{~g} / \mathrm{L}$ glucose, as well as $5.0 \mathrm{~g} / \mathrm{L}$ glycine and $10.0 \mathrm{~g} / \mathrm{L}$ succinic acid were added. The supernatant containing ALA was harvested after $48 \mathrm{~h}$ of fermentation. The experiments were carried out in triplicate and the ALA produced by the culture was quantified using a classical method (Mauzerall and Granick, 1956).

\section{REFERENCES}

Bassalo, M. C., Garst, A. D., Halweg-Edwards, A. L., Grau, W. C., Domaille, D. W., Mutalik, V. K., et al. (2016). Rapid and efficient one-step metabolic pathway integration in E. coli. ACS Synth. Biol. 5, 561-568. doi: 10.1021/acssynbio. 5 b00187

Cai, L., Tan, D., Aibaidula, G., Dong, X.-R., Chen, J.-C., Tian, W.-D., et al. (2011). Comparative genomics study of polyhydroxyalkanoates (PHA) and ectoine relevant genes from Halomonas sp. TD01 revealed extensive horizontal gene transfer events and co-evolutionary relationships. Microb. Cell Fact. 10:88. doi: 10.1186/1475-2859-10-88

Cha, J.-S., Pujol, C., and Kado, C. I. (1997). Identification and characterization of a Pantoea citrea gene encoding glucose dehydrogenase that is essential

\section{Editing the Genome of Halomonas bluephagenesis}

The procedures for genome editing of $H$. bluephagenesis using the method based on CRISPR-Cas12a were developed according to that based on CRIPSR-Cas9 (Qin et al., 2018). Generally, the helper plasmid pTD-Cas12a was introduced into H. bluephagenesis TD01 by conjugation, followed by the donor plasmid pTtd-prpC or pTtd-prpC-PM (Table 1). After at least $36 \mathrm{~h}$ of incubation, the resulting colonies were genotyped by PCR.

\section{AUTHOR CONTRIBUTIONS}

$\mathrm{XA}, \mathrm{YY}, \mathrm{YG}$, and QW designed the experiments. XA, YY, TL, YG, T-TY, XD, and Z-TZ performed the experiments. G-QC contributed intellectual input. XA interpreted the results and wrote the paper.

\section{FUNDING}

This work was supported by the National Natural Science Foundation of China (Grants Nos. 31470933 and 31170940), the National High Technology Research and Development (863 Program) (Grants Nos. 2012AA020503, 2013AA020301, and 2012AA02A702), the 973 Basic Research Fund (Grant No. 2012CB725200), and the Tsinghua University Initiative Scientific Research Program (Grant No. 20131089199).

\section{ACKNOWLEDGMENTS}

We thank Dr. Barry Wanner for providing plasmid pKD46. We thank Dr. Jun-Xiang Li (Tsinghua University) and Dr. Ivan Hajnal (Yiwen expert text solutions) for critical reading and correction of the manuscript. We also thank Qin Qin and Yong Chen for assistance in editing the genome of H. bluephagenesis.

\section{SUPPLEMENTARY MATERIAL}

The Supplementary Material for this article can be found online at: https://www.frontiersin.org/articles/10.3389/fmicb. 2018.02307/full\#supplementary-material

for causing pink disease of pineapple. Appl. Environ. Microbiol. 63, 71-76.

Chayot, R., Montagne, B., Mazel, D., and Ricchetti, M. (2010). An end-joining repair mechanism in Escherichia coli. Proc. Natl. Acad. Sci. U.S.A. 107, $2141-$ 2146. doi: 10.1073/pnas.0906355107

Chen, J. S., Ma, E., Harrington, L. B., Da Costa, M., Tian, X., Palefsky, J. M., et al. (2018). CRISPR-Cas12a target binding unleashes indiscriminate single-stranded DNase activity. Science 360, 436-439. doi: 10.1126/science. aar6245

Chung, M. E., Yeh, I., Sung, L. Y., Wu, M. Y., Chao, Y. P., Ng, I. S., et al. (2017). Enhanced integration of large DNA into E. coli chromosome by CRISPR/Cas9. Biotechnol. Bioeng. 114, 172-183. doi: 10.1002/bit. 26056 
Cui, L., and Bikard, D. (2016). Consequences of Cas9 cleavage in the chromosome of Escherichia coli. Nucleic Acids Res. 44, 4243-4251. doi: 10.1093/nar/ gkw223

Datsenko, K. A., and Wanner, B. L. (2000). One-step inactivation of chromosomal genes in Escherichia coli K-12 using PCR products. Proc. Natl. Acad. Sci. U.S.A. 97, 6640-6645. doi: 10.1073/pnas.120163297

Englaender, J. A., Jones, J. A., Cress, B. F., Kuhlman, T. E., Linhardt, R. J., and Koffas, M. A. (2017). Effect of genomic integration location on heterologous protein expression and metabolic engineering in E. coli. ACS Synth. Biol. 6, 710-720. doi: 10.1021/acssynbio.6b00350

Enyeart, P. J., Chirieleison, S. M., Dao, M. N., Perutka, J., Quandt, E. M., Yao, J., et al. (2013). Generalized bacterial genome editing using mobile group II introns and Cre-lox. Mol. Syst. Biol. 9:685. doi: 10.1038/msb. 2013.41

Esvelt, K. M., and Wang, H. H. (2013). Genome-scale engineering for systems and synthetic biology. Mol. Syst. Biol. 9:641. doi: 10.1038/msb.20 12.66

Fonfara, I., Richter, H., Bratovič, M., Le Rhun, A., and Charpentier, E. (2016). The CRISPR-associated DNA-cleaving enzyme Cpf1 also processes precursor CRISPR RNA. Nature 532:517. doi: 10.1038/nature17945

Ganusov, V. V., and Brilkov, A. V. (2002). Estimating the instability parameters of plasmid-bearing cells. I. Chemostat culture. J. Theor. Biol. 219, 193-205. doi: $10.1006 /$ jtbi.2002.3101

Gao, Y., and Zhao, Y. (2014). Self-processing of ribozyme-flanked RNAs into guide RNAs in vitro and in vivo for CRISPR-mediated genome editing. J. Integr. Plant Biol. 56, 343-349. doi: 10.1111/jipb.12152

Godwin, D., and Slater, J. H. (1979). The influence of the growth environment on the stability of a drug resistance plasmid in Escherichia coli K12. Microbiology $111,201-210$

Grote, A., Hiller, K., Scheer, M., Münch, R., Nörtemann, B., Hempel, D. C., et al. (2005). JCat: a novel tool to adapt codon usage of a target gene to its potential expression host. Nucleic Acids Res. 33(Suppl. 2), W526-W531. doi: 10.1093/nar/ gki376

Guzman, L.-M., Belin, D., Carson, M. J., and Beckwith, J. (1995). Tight regulation, modulation, and high-level expression by vectors containing the arabinose PBAD promoter. J. Bacteriol. 177, 4121-4130. doi: 10.1128/jb.177.14.41214130.1995

Heermann, R., Zeppenfeld, T., and Jung, K. (2008). Simple generation of site-directed point mutations in the Escherichia coli chromosome using $\operatorname{Red}^{\circledR} /$ ET $^{\circledR}$ recombination. Microb. Cell Fact. 7:14. doi: 10.1186/1475-28 59-7-14

Jiang, W., Bikard, D., Cox, D., Zhang, F., and Marraffini, L. A. (2013). RNA-guided editing of bacterial genomes using CRISPR-Cas systems. Nat. Biotechnol. 31, 233-239. doi: 10.1038/nbt.2508

Jiang, Y., Chen, B., Duan, C., Sun, B., Yang, J., and Yang, S. (2015). Multigene editing in the Escherichia coli genome via the CRISPR-Cas9 system. Appl. Environ. Microbiol. 81, 2506-2514. doi: 10.1128/AEM.04 023-14

Jinek, M., Chylinski, K., Fonfara, I., Hauer, M., Doudna, J. A., and Charpentier, E. (2012). A programmable dual-RNA-guided DNA endonuclease in adaptive bacterial immunity. Science 337, 816-821. doi: 10.1126/science. 1225829

Karberg, M., Guo, H., Zhong, J., Coon, R., Perutka, J., and Lambowitz, A. M. (2001). Group II introns as controllable gene targeting vectors for genetic manipulation of bacteria. Nat. Biotechnol. 19, 1162-1167. doi: 10.1038/nbt12011162

Li, T., Guo, Y.-Y., Qiao, G.-Q., and Chen, G.-Q. (2016). Microbial synthesis of 5-aminolevulinic acid and its coproduction with polyhydroxybutyrate. ACS Synth. Biol. 5, 1264-1274. doi: 10.1021/acssynbio.6b00105

Li, Y., Lin, Z., Huang, C., Zhang, Y., Wang, Z., Tang, Y. J., et al. (2015). Metabolic engineering of Escherichia coli using CRISPR-Cas9 meditated genome editing. Metab. Eng. 31, 13-21. doi: 10.1016/j.ymben.2015.06.006

Liu, C. C., Qi, L., Yanofsky, C., and Arkin, A. P. (2011). Regulation of transcription by unnatural amino acids. Nat. Biotechnol. 29, 164-168. doi: 10.1038/nbt. 1741

Liu, S., Zhang, G., Li, X., and Zhang, J. (2014). Microbial production and applications of 5-aminolevulinic acid. Appl. Microbiol. Biotechnol. 98, 73497357. doi: 10.1007/s00253-014-5925-y
Marsić, N., Roje, S., Stojiljković, I., Salaj-Smic, E., and Trgovcević, Z. (1993). In vivo studies on the interaction of RecBCD enzyme and lambda Gam protein. J. Bacteriol. 175, 4738-4743. doi: 10.1128/jb.175.15.4738-4743. 1993

Mauzerall, D., and Granick, S. (1956). The occurrence and determination of $\delta$-aminolevulinic acid and porphobilinogen in urine. J. Biol. Chem. 219, 435-446.

Mojica, F. J., García-Martínez, J., and Soria, E. (2005). Intervening sequences of regularly spaced prokaryotic repeats derive from foreign genetic elements. J. Mol. Evol. 60, 174-182. doi: 10.1007/s00239-004-0046-3

Murphy, K. C. (1991). Lambda Gam protein inhibits the helicase and chistimulated recombination activities of Escherichia coli RecBCD enzyme. J. Bacteriol. 173, 5808-5821. doi: 10.1128/jb.173.18.5808-5821.1991

Murphy, K. C. (1998). Use of bacteriophage $\lambda$ recombination functions to promote gene replacement in Escherichia coli. J. Bacteriol. 180, 2063-2071.

Port, F., and Bullock, S. L. (2016). Augmenting CRISPR applications in Drosophila with tRNA-flanked sgRNAs. Nat. Methods 13, 852-854. doi: 10.1038/nmeth. 3972

Pósfai, G., Kolisnychenko, V., Bereczki, Z., and Blattner, F. R. (1999). Markerless gene replacement in Escherichia coli stimulated by a double-strand break in the chromosome. Nucleic Acids Res. 27, 4409-4415. doi: 10.1093/nar/27.22. 4409

Puigbo, P., Guzman, E., Romeu, A., and Garcia-Vallve, S. (2007). OPTIMIZER: a web server for optimizing the codon usage of DNA sequences. Nucleic Acids Res. 35(Web Server issue), W126-W131. doi: 10.1093/nar/gkm219

Pyne, M. E., Moo-Young, M., Chung, D. A., and Chou, C. P. (2015). Coupling the CRISPR/Cas9 system with lambda red recombineering enables simplified chromosomal gene replacement in Escherichia coli. Appl. Environ. Microbiol. 81, 5103-5114. doi: 10.1128/AEM.01248-15

Qin, Q., Ling, C., Zhao, Y., Yang, T., Yin, J., Guo, Y., et al. (2018). CRISPR/Cas9 editing genome of extremophile Halomonas spp. Metab. Eng. 47, 219-229. doi: 10.1016/j.ymben.2018.03.018

Reisch, C. R., and Prather, K. L. (2015). The no-SCAR (Scarless Cas9 assisted recombineering) system for genome editing in Escherichia coli. Sci. Rep. 5:15096. doi: 10.1038/srep15096

Sharan, S. K., Thomason, L. C., Kuznetsov, S. G., and Court, D. L. (2009). Recombineering: a homologous recombination-based method of genetic engineering. Nat. Protoc. 4, 206-223. doi: 10.1038/nprot.2008.227

Stahl, M. M., Thomason, L., Poteete, A. R., Tarkowski, T., Kuzminov, A., and Stahl, F. W. (1997). Annealing vs. invasion in phage lambda recombination. Genetics 147, 961-977.

Sukhija, K., Pyne, M., Ali, S., Orr, V., Abedi, D., Moo-Young, M., et al. (2012). Developing an extended genomic engineering approach based on recombineering to knock-in heterologous genes to Escherichia coli genome. Mol. Biotechnol. 51, 109-118. doi: 10.1007/s12033-011-9442-2

Wang, H. H., Isaacs, F. J., Carr, P. A., Sun, Z. Z., Xu, G., Forest, C. R., et al. (2009). Programming cells by multiplex genome engineering and accelerated evolution. Nature 460, 894-898. doi: 10.1038/nature08187

Xu, L., Zhao, L., Gao, Y., Xu, J., and Han, R. (2017). Empower multiplex cell and tissue-specific CRISPR-mediated gene manipulation with self-cleaving ribozymes and tRNA. Nucleic Acids Res. 45:e28.

Yan, M.-Y., Yan, H.-Q., Ren, G.-X., Zhao, J.-P., Guo, X.-P., and Sun, Y.-C. (2017). CRISPR-Cas12a-assisted recombineering in bacteria. Appl. Environ. Microbiol. 83:e947-17. doi: 10.1128/AEM.00947-17

Yang, J., Sun, B., Huang, H., Jiang, Y., Diao, L., Chen, B., et al. (2014). Highefficiency scarless genetic modification in Escherichia coli by using lambda red recombination and I-SceI cleavage. Appl. Environ. Microbiol. 80, 3826-3834. doi: 10.1128/AEM.00313-14

Yu, B. J., Kang, K. H., Lee, J. H., Sung, B. H., Kim, M. S., and Kim, S. C. (2008). Rapid and efficient construction of markerless deletions in the Escherichia coli genome. Nucleic Acids Res. 36:e84. doi: 10.1093/nar/gkn359

Yu, J., Qian, F., Yang, J., Liu, Y., Feng, D., Xu, C., et al. (2017). CRISPR-Cpf1 assisted genome editing of Corynebacterium glutamicum. Nat. Commun. 8:15179. doi: 10.1038/ncomms15179

Zetsche, B., Gootenberg, J. S., Abudayyeh, O. O., Slaymaker, I. M., Makarova, K. S., Essletzbichler, P., et al. (2015). Cpf1 is a single RNA-guided endonuclease of a class 2 CRISPR-Cas system. Cell 163, 759-771. doi: 10.1016/j.cell.2015. 09.038 
Zhang, H., Cheng, Q.-X., Liu, A.-M., Zhao, G.-P., and Wang, J. (2017). A novel and efficient method for bacteria genome editing employing both CRISPR/Cas9 and an antibiotic resistance cassette. Front. Microbiol. 8:812. doi: 10.3389/fmicb. 2017.00812

Zhang, Y., Buchholz, F., Muyrers, J. P., and Stewart, A. F. (1998). A new logic for DNA engineering using recombination in Escherichia coli. Nat. Genet. 20, 123-128. doi: 10.1038/2417

Zhao, D., Yuan, S., Xiong, B., Sun, H., Ye, L., Li, J., et al. (2016). Development of a fast and easy method for Escherichia coli genome editing with CRISPR/Cas9. Microb. Cell Fact. 15:205. doi: 10.1186/s12934-0160605-5
Conflict of Interest Statement: The authors declare that the research was conducted in the absence of any commercial or financial relationships that could be construed as a potential conflict of interest.

Copyright (c) 2018 Ao, Yao, Li, Yang, Dong, Zheng, Chen, Wu and Guo. This is an open-access article distributed under the terms of the Creative Commons Attribution License (CC BY). The use, distribution or reproduction in other forums is permitted, provided the original author(s) and the copyright owner(s) are credited and that the original publication in this journal is cited, in accordance with accepted academic practice. No use, distribution or reproduction is permitted which does not comply with these terms. 